\title{
OPERATION OF THE AIRBORNE 355-NM HIGH SPECTRAL RESOLUTION AND DOPPLER LIDAR LNG
}

\author{
D. Bruneau (1), J. Pelon (1),
}

\author{
F. Blouzon (2), Q. Cazenave (1), H. Collomb (1), A. Irbah (1), J-F Mariscal (1), J. Delanoë (1) \\ 1 - LATMOS, Sorbonne Université-CNRS-UVSQ Paris, 2DT-INSU, CNRS, Meudon, France
}

\begin{abstract}
High spectral resolution lidar (HSRL) are known to offer capabilities of separating attenuated aerosol and molecular backscattering so that particle extinction and backscattering can be separately retrieved. UV operation provides high energy in eye-safety conditions. Further to that, it could be important for most meteorological or environmental studies to get wind measurements at the same time. LNG is now the only HSR Doppler Lidar (HSRDL) system capable of this. Results obtained during groundbased and airborne measurements show that the backscatter and extinction coefficients at $355 \mathrm{~nm}$ can be measured with a relative precision better than $10 \%$ (adjusting altitude and time resolution from 60 $\mathrm{m}$ to $240 \mathrm{~m}$ and $30 \mathrm{~s}$ to $2 \mathrm{mn}$, respectively) in aerosol layers of $0.510^{-6} \mathrm{~m}^{-1} \mathrm{sr}^{-1}$ backscatter coefficient from ground and aircraft. The same relative precision is obtained in cirrus clouds of a $10^{-5} \mathrm{~m}^{-1} \mathrm{sr}^{-1}$ backscatter coefficient. The capacity of the system to perform wind velocity measurements has also been demonstrated with precisions in the range of 1 to $2 \mathrm{~ms}^{-1}$ in same conditions. We present the main characteristics and illustrate observational capabilities from ground-based and airborne measurements.
\end{abstract}

\section{Instrument}

The High Spectral Resolution (HSR) lidar technique allows to differentiate molecular and particular scattering thus improving aerosol or cloud extinction and backscatter coefficients retrieval which are critical parameters for environmental and meteorological studies. The first airborne HSR lidar systems were developed at DLR in Europe [1] and NASA in the USA [2 ]. The LNG system is based on the use of a Mach-Zehnder interferometer (MZI) as a spectral discriminator $[3,4]$. This presents the advantage to not require any frequency locking between the emitter and the interferometer and is moreover compatible with a multimode laser emission [5].

Measurement method, system description and first results can be found in $[3,6]$. We focus here on new results from ground-based and airborne field experiments presenting both scattering and wind measurements.

LNG is a three-wavelength $(1064 \mathrm{~nm}, 532 \mathrm{~nm}$ and $355 \mathrm{~nm}$ ) backscatter lidar with polarization analysis at $355 \mathrm{~nm}$. The HSR capability, based on a MZI, has been added at $355 \mathrm{~nm}$ following a previous concept analysis [3]. The lidar is designed to be installed in the Falcon 20 or ATR 42 aircraft of SAFIRE, the French research aircraft service.

\section{A. Emitter}

The emitter is based on a Quantel Nd:YAG QSwitched oscillator, injection seeded with a $\mathrm{CW}$ narrow-line emission. It provides single longitudinal mode pulses with $7 \mathrm{~ns}$ duration and a $70 \mathrm{MHz}$ linewidth. The fundamental infrared emission is directed though second and third harmonic generators and then through a beam expander. The emitted energy at $355 \mathrm{~nm}$ is about50mJ@20 Hz, with a divergence smaller than $0.2 \mathrm{mrd}$. at the beam expander output. The divergence at 532 and 1064 is larger (4 and 5.5 mrd, respectively, to reduce eye-safety distance to a few hundred meters.

\section{B. Receiver}

The backscattered light is collected by a Cassegrain telescope with a $300 \mathrm{~mm}$ aperture. Behind the telescope focus, an optical package (receiving optics, RO) ensures the separation of the wavelengths, the background light spectral and spatial filtering and the parallel and cross polarization separation at $355 \mathrm{~nm}$. The receiver field-of view is increased at 532 and $1064 \mathrm{~nm}$, accordingly to emission. This difference in field-of-views allows particle size estimates from multiple scattering analyses.

\section{MZI design}

The actual MZI design, detailed in [6], has an optical path difference (OPD) $\Delta=20 \mathrm{~cm}$ and is field compensated in order to accept the large fiber diameter input without reduction of interference contrast. The MZI optical components and the detectors are mounted in a temperature stabilized box $\left(+/-0.1{ }^{\circ} \mathrm{C}\right)$. 


\section{Measurement principle}

According to (3), the signal delivered by each channel, for $i=1$ to 4 , can be written

$$
S_{i}=\frac{S_{t}}{4} a_{i}\left[1+M_{i} M_{a} \sin \left(\varphi+(i-1) \frac{\pi}{2}\right)\right]
$$

with $\mathrm{S}_{\mathrm{t}}$ the total signal, and $\mathrm{a}_{\mathrm{i}}, \mathrm{M}_{\mathrm{i}}$ the relative photometric sensitivity and instrumental interference contrast of channel i, respectively. $M_{a}$ is the interference contrast given by the atmospheric backscattered signal and $\varphi$ the interference phase. The four signals are combined two-by-two in order to produce a complex signal Q (with in-phase and quadrature components), whose modulus is the contrast given by the atmospheric signal:

Always according to [3], the OPD of $20 \mathrm{~cm}$ has been chosen so that the interference contrast given by the molecular scattering is null. As the spectral broadening of the particulate scattering is negligible, the resulting contrast is equal to the instrumental contrast produced by the laser itself. Thus, the retrieved contrast $\mathrm{M}_{\mathrm{a}}$ is equal to the particulate to total backscatter ratio (PBR) :

$$
M_{a}=|Q|=P B R=\frac{\beta_{p}}{\beta_{m}+\beta_{p}}=\frac{R-1}{R}
$$

where $\mathrm{R}$ is the usual lidar backscatter ratio $(\mathrm{R}=1+\beta \mathrm{p} / \beta \mathrm{m})$ and $\beta \mathrm{m}, \beta \mathrm{p}$ are the molecular and particulate backscatter coefficient, respectively. This result is independent of the exact molecular linewidth and line-shape provided it is sufficiently large to yield a null contrast. This avoids the necessity of precise line-shape modeling based otherwise needed $[3,4]$. Note also that the PBR retrieval is not affected by a Doppler shift of the signal caused by the platform motion and pointing, which is of importance for an airborne instrument.

In addition to the contrast, the interference phase $\varphi$, is obtained by the argument of the complex signal Q. Subtracting the reference interference phase $\varphi_{r}$, obtained on a highly attenuated pick-up of the laser emission one can obtain the Line-of-sight particles velocity $\mathrm{V}_{\text {LOS }}$ with:

$$
\varphi-\varphi_{r}=\frac{2 \pi \Delta}{\lambda_{0}}\left(1+\frac{2 V_{L O S}}{c}\right)
$$

This ensures the Doppler measurement capability with the same MZI device. Of course the phase can only be measured when a significant interference contrast occurs, i.e. on particulate backscattering, but in this case, it is independent of the backscatter ratio.

\section{B. Calibration and signal processing}

Before processing actual atmospheric signals, it is necessary to perform a calibration of the MZI for determining the $\mathrm{a}_{\mathrm{i}}, \mathrm{M}_{\mathrm{i}}$ parameters in Eq. (1). For this purpose we record the reference signal on the 4 channels on long time series. A fit of the recorded signals with the model described by Eq. (1) is obtained with a correlation better than $99.9 \%$ that allows determining the $\mathrm{a}_{\mathrm{i}}$ and $\mathrm{M}_{\mathrm{i}}$ parameters. With an atmospheric density model, we can calculate $\beta_{\mathrm{m}}$ (only dependent of molecular density) as a function of altitude. The attenuated particulate signal $S_{p a r}$ and attenuated molecular signal $\mathrm{S}_{\mathrm{mol}}$ can then be obtained as

$S_{\text {par }}=M_{a} S_{\text {tot }}$ and $S_{\text {mol }}=\left(1-M_{a}\right) S_{\text {tot }}$

with

$S_{\text {tot }}=\frac{4}{M_{1}^{-1}+M_{2}^{-1}+M_{3}^{-1}+M_{4}^{-1}}\left(\frac{S_{1}}{a_{1} M_{1}}+\frac{S_{2}}{a_{2} M_{2}}+\frac{S_{3}}{a_{3} M_{3}}+\frac{S_{4}}{a_{4} M_{4}}\right)(5)$

\section{Scattering measurements}

We first present here the measurements performed during tests performed on May 11, 2016 from ground.

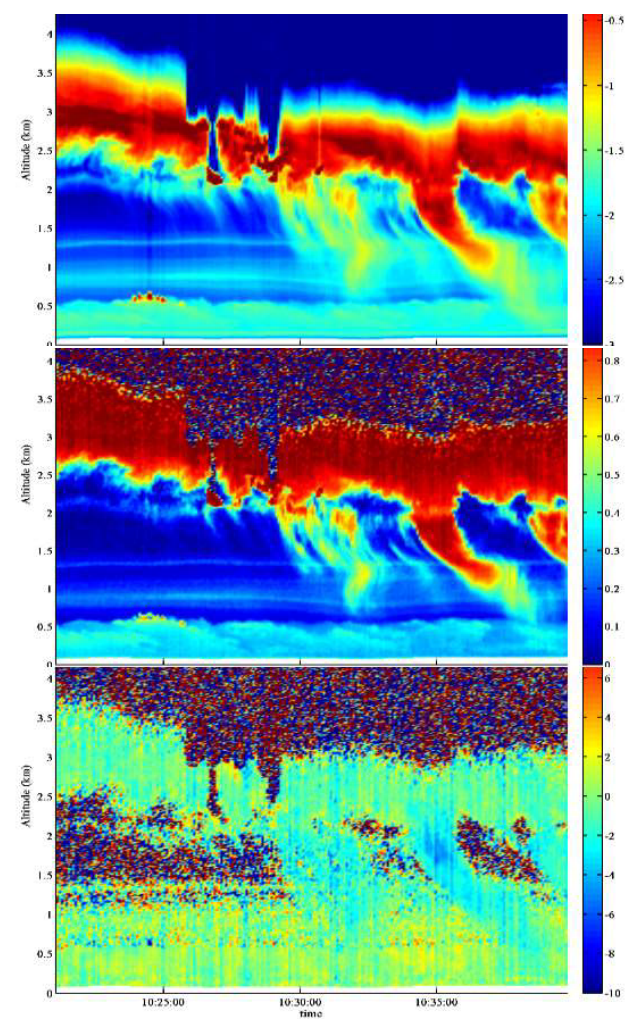

Fig. 1 : (top plot) Time-altitude cross-section of the logarithm of the $1064 \mathrm{~nm}$ range-corrected signals showing precipitating altostratus cloud above the $500 \mathrm{~m}$ high boundary layer ; (middle plot) UV contrast M determined from MZI and (bottom plot) vertical air speed retrieved in the cloud and boundary layer. A $20 \mathrm{mn}$ sequence of $\mathrm{G} / \mathrm{B}$ measurements is shown for 11 May 2016. 
The cross-section of the $1064 \mathrm{~nm}$ backscatter signals over the whole test duration is presented in Fig 1 (top panel). The aerosol layers can be clearly identified below $1.5 \mathrm{~km}$ from the 1064 $\mathrm{nm}$ signal and on the $355 \mathrm{~nm}$ MZI contrast. One can see that the boundary layer top is detected from the signal gradient at about $500 \mathrm{~m}$ above surface. The contrast M of MZI measurements shows a good dynamics from less than 0.02 to about 1 near cloud top. It allows retrieving the particle backscatter coefficient using Eq. (3). Vertical upward motions are seen in the boundary layer and above, the Doppler shift associated with the precipitations can also be clearly observed.

The $355 \mathrm{~nm}$ HSR analysis shows a weak PBR value above the boundary layer, increasing in the cloud up to 0.9 , corresponding to an average backscatter ratio $=10$ and to a particulate backscatter coefficient of $10^{-1} \mathrm{~km}^{-1} \cdot \mathrm{sr}^{-1}$. The HSR vertical profiles of particulate backscatter $\left(\beta_{p}\right)$ and extinction $\left(\alpha_{p}\right)$ coefficients at $355 \mathrm{~nm}$ and the related errors (standard deviation) profiles are presented in Fig. 2 for an averaging over 1 minute. The vertical resolutions are $60 \mathrm{~m}$ and $240 \mathrm{~m}$ for $\beta_{\mathrm{p}}$ and $\alpha_{\mathrm{p}}$, respectively. Random errors caused by the detection noise are calculated according to the equations developed in [3], from the total sensitivity of the detection channel and the number of photo-electrons derived from the recorded analog signals.

The particular depolarization ratio varies from $20 \%$ to $30 \%$ in the cloud. Results show that for long measurement series, the contrast and speed exhibit negligible biases even under variable environmental conditions.

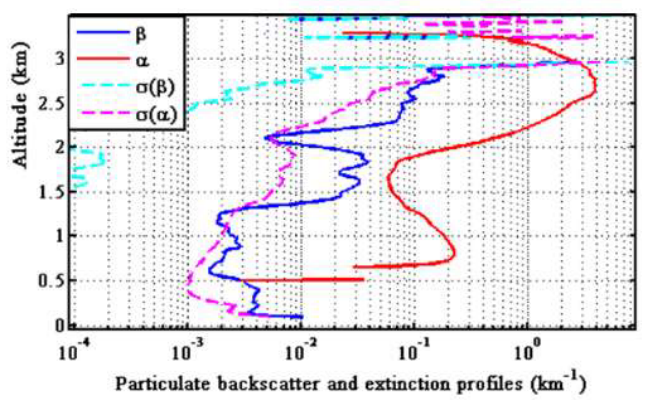

Fig. 2 : Profiles of HSR measurements over the aerosol layer a) particulate backscatter coefficient $\left(\mathrm{km}^{-1} \mathrm{sr}^{-1}\right)$ and extinction coefficient $\left(\mathrm{km}^{-1}\right)$ with related errors (standard deviation).

\section{Airborne measurements}

Pointing can be done in nadir or slant viewing ( $37^{\circ}$ inclination angle) modes. We present here the measurements performed in nadir viewing mode during test flights in 2014-2015 and during the NAWDEX/EPATAN field experiment in 2016 [7].

\section{A. Verification of ground echo speed}

As a preliminary check of the HSR Doppler performance, measurements of the apparent ground speed Vs during flights over land have shown that the mean difference between the apparent ground speed calculated from the aircraft navigation data and measured by the lidar is $0.1-0.15 \mathrm{~ms}^{-1}$ with a standard deviation of about $1.5 \mathrm{~ms}^{-1}$.

\section{B. Cloud microphysics}

Flight of 16 October 2016 has been used to perform a multiple field of view analysis. Two ratios are calculated from measured signals: the $532 / 355 \mathrm{~nm}$ and the $1064 / 532 \mathrm{~nm}$. The first one is sensitive to multiple scattering, whereas the second is not due to their similar field of views, and can be used as a reference.

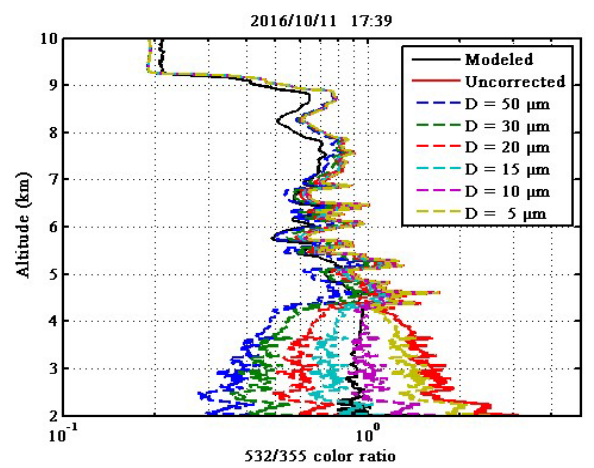

Fig3.: Ratio of the 532 to $355 \mathrm{~nm}$ in a mid-level altostratus (below $4.5 \mathrm{~km}$ ) and calculation using the forward scattering model.

Fig. 3 shows that the correction of the $355 / 532$ $\mathrm{nm}$ ratio using the Hogan model [8] allows to bring values close to the 532/1064 nm, indicative of particle size of about $20 \mu \mathrm{m}$.

\section{Wind speed measurements on VAD}

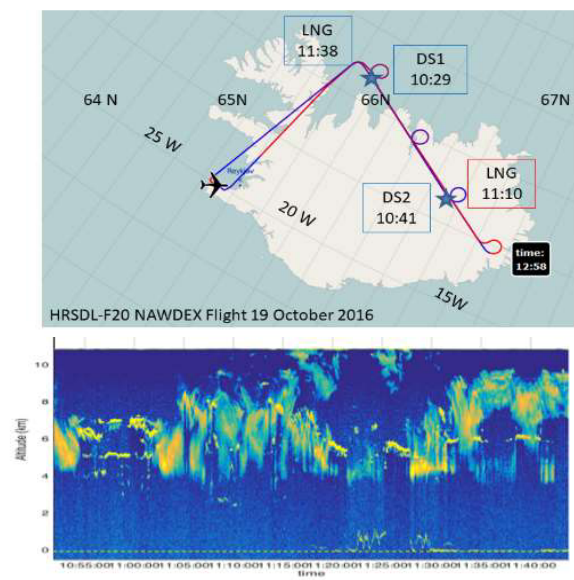

Fig. 3 : Flight plan and circle (top) made by the F20 to perform VAD measurements with LNG in vertical pointing. 
Dropsonde launches have been performed on the way to the south-east part of Iceland, whereas VADs have been made on the way back. Backscatter signal in observed cirrus derived from contrast measurements using MZI after roll angle corrections in the four VADs.

During the flight of October $30^{\text {th }}, 2016$ (track is reported in Fig. 3 (top panel)), the F20 was flying over cirrus clouds over Iceland. Four wind profiles were performed during this flight using the lidar VAD technique on $360^{\circ}$ aircraft turns together with two dropsonde launches. Results are presented in Fig. 4.
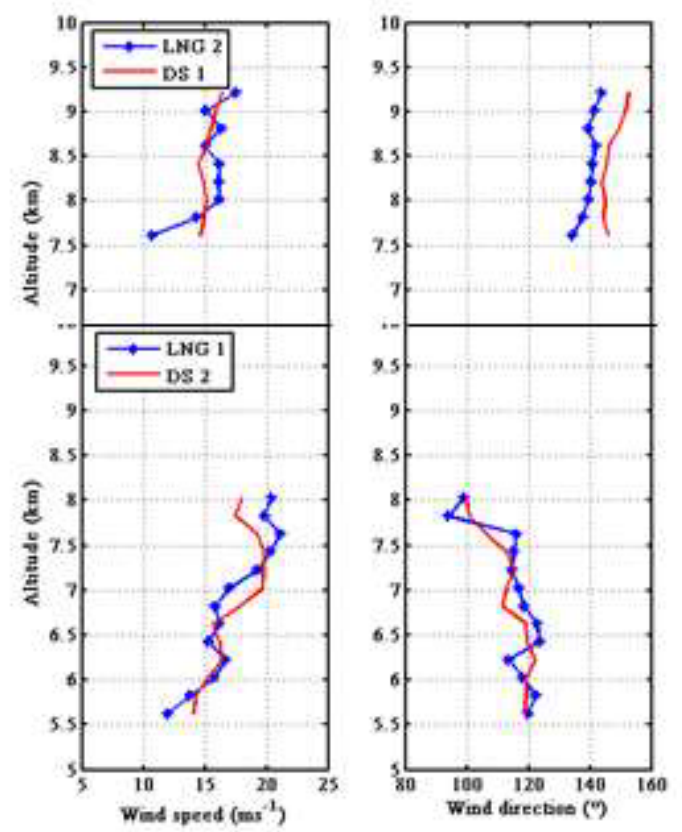

Fig. 4: Vertical profiles of wind speed and direction retrieved from VADs 1 and 3 . Note that VAD 3 is closer in time and space to the dropsonde launch.

Comparison between VAD lidar measurement and dropsonde profiles show an excellent agreement, in both wind speed and direction for DS2 closer in time with lidar measurements.

\section{Conclusion}

The measurement capabilities of the 3wavelength 2-polarisation HSR Doppler airborne lidar LNG have been successfully demonstrated during field campaigns. Results show that the backscatter and extinction coefficients at $355 \mathrm{~nm}$ can be measured with a relative precision of $10 \%$ for $60 \mathrm{~m}$ and $240 \mathrm{~m}$ vertical resolution respectively in aerosol layers of $10-6 \mathrm{~m}^{-1} \cdot \mathrm{sr}^{-1}$ backscatter coefficient with a 30 $\mathrm{km}$ horizontal resolution. The same precision with the same vertical resolution is obtained in cirrus clouds 2 10-5 m $\mathrm{m}^{-1} \cdot \mathrm{sr}^{-1}$ backscatter coefficient with a horizontal resolution of $5 \mathrm{~km}$. The Doppler measurement capability has also been demonstrated. The velocity measurement is performed on the particle backscattering and its precision is strongly dependent on the backscattering ratio. In favorable conditions, LOS wind velocity measurements can be made with a precision in the range of 1 to $2 \mathrm{~ms}^{-1}$. VADs provide accurate profiles of wind components. LOS speed measurements performed on ground echoes show averaged biases less than $0.15 \mathrm{~ms}^{-1}$. This instrument is particularly matched for the cloud studies in combination with cloud radar as planned in the ongoing RALI project [8]. It is planned to be used for aerosol-cloud process studies and for the validation of the ESA space-borne ADMAeolus and Earthcare-ATLID lidars. In this frame, further comparisons with ground-based and other airborne instruments are planned to ensure the validation process.

\section{Acknowledgements}

Development and test flight of LNG have been supported by INSU and CNES which are acknowledged. The authors also wish to thank the technical support of the Division Technique for the development and flights of the HRSDLNG and the SAFIRE group for its assistance during the airborne campaign. NAWDEX-EPATAN flights were supported by ESA (Contract No. 4000119015/NL/CT/gp), we particularly acknowledge.

\section{References}

[1] M. Esselborn, M. Wirth, A. Fix, M. Tesche, and G. Ehret, "Airborne high spectral resolution lidar for measuring aerosol extinction and backscatter coefficients," Appl. Opt. 47, 346-358 (2008).

[2] J. W. Hair, C. A. Hostetler, A. L. Cook, D. B. Harper, R. A. Ferrare, T. L. Mack, W. Welch, L. R. Izquierdo, and F. E. Hovis, "Airborne high spectral resolution lidar for profiling aerosol optical properties," Appl. Opt. 47, 6734-6752, (2008).

[3] D.Bruneau and J. Pelon, "Simultaneous measurements of particle backscattering and extinction coefficients and wind velocity by lidar with a Mach-Zehnder interferometer: principle of operation and performance assessment", Appl. Opt., 42, 11011114 (2003).

[4] D. Bruneau, A. Garnier, A. Hertzog, and J. Porteneuve, "Wind-velocity lidar measurements by use of a Mach-Zehnder interferometer, comparison with a Fabry-Perot interferometer", Appl. Opt., 43, 1, 173-182, (2004)

[5] D. Bruneau, F. Blouzon, J. Spatazza, F. Montmessin, J.Pelon and B. Faure, "Direct-detection wind lidar operating with a multimode laser", Appl. Opt., 52, 4941-4949, (2013).

[6] D.Bruneau, J. Pelon, F. Blouzon, J. Spatazzan, P. Genau, G. Buchholtz, N. Amarouche, A. Abchiche and O.Aouji, "355 nm high spectral resolution airborne lidar LNG: system description and first results", Appl. Opt. 54, 8776-8785, (2015)

[7] Schäfler and co-authors, The North Atlantic Waveguide and Downstream Impact Experiment, Bull. Amer. Met. Soc., 16071637, doi.org/10.1175/, 2018.

[8] Hogan, R. J., 2006: Fast approximate calculation of multiply scattered lidar returns. Appl. Opt., 45, 5984-5992.

[9] Protat A.; Pelon J., Testud J.; Grand N., Delville P.; Laborie P., Vinson J.-P., Bouniol D.; Bruneau D.; Chepfer H.; Delanoe J.; Haeffelin M., Noel V. and Tinel C., 2004 : Le projet RALI : Combinaison d'un radar nuage et d'un lidar pour l'étude des nuages faiblement précipitants, La Météorologie, $n^{\circ}$ 47, 23-33. 